\title{
Determinants of functional independence and quality of life in children with spina bifida
}

\author{
M Schoenmakers*, C Uiterwaal, R Gooskens and P Helders
}

\author{
Address: Wilhelmina Children's Hospital, University Medical Center, Utrecht, Utrecht, The Netherlands \\ Email: M Schoenmakers* - M.A.G.C.Schoenmakers@wkz.azu.nl \\ * Corresponding author
}

from 48th Annual Meeting of the Society for Research into Hydrocephalus and Spina Bifida

Dublin, Ireland, 23-26 June 2004

Published: 23 December 2004

Cerebrospinal Fluid Research 2004, I(SuppI I):S63 doi:I0.I 186/1743-8454-I-SI-S63

This article is available from: http://www.cerebrospinalfluidresearch.com/content/I/SI/S63

\section{Objectives}

To investigate determinants of functional independence and study which functional abilities were determinants for 'health related quality of life' in children with myelomeningocele.

\section{Design}

Cross-sectional study by means of clinical assessment, 'disability' measurement, and questionnaires.

\section{Setting}

Outpatient spina bifida clinic at a university hospital.

\section{Participants}

122 children with myelomeningocele. Mean age 7.9; range $1-18$ years.

\section{Main Outcome Measures}

Functional independence as measured by the 'Pediatric Evaluation of Disability Inventory' (PEDI), and 'Health Related Quality of Life Questionnaire' (HRQL). Uni- and multivariate logistic regression models were used to investigate factors that were determinants for these outcomes. Results were expressed as odds ratios and $95 \%$ confidence intervals $(\mathrm{Cl})$.

\section{Results}

Lesion level below L3 (OR: 0.4, Cl: 0.1-1.0), mental status of IQ > 80 (OR: 4.2, Cl: 1.2-14.9), having no contractures in lower extremities (OR: 3.4, Cl: 1.3-8.8), and having normal strength of knee extensor muscles (OR: 4.1, Cl: 1.4-11.5), were most strongly associated with independence in self-care. Mental status (OR: 16.1, Cl: 2.8-93.9), having no contractures in lower extremities (OR 1.5, Cl: 1.4-5.3), and normal strength in knee extensors (OR: 11.0, Cl: 1.3-97.0), were the most important determi- nants for independence in mobility. Concerning functional abilities, being independent with regard to mobility was the most important determinant for HRQL (OR: 5.3, Cl: 1.6-17.4).

\section{Conclusions}

In children with myelomeningocele, good muscle strength, mental ability and being independent in mobility, appeared to be much more important for daily life function and quality of life than other medical indicators of the disorder. This information is of clinical significance in planning a comprehensive and realistic rehabilitation program. 